\title{
Factors influencing decisions of Laotian patients to use health care services in Thailand
}

\author{
Suwaree Charoenmukayananta ${ }^{\mathrm{a}}$, Jiruth Sriratanaban ${ }^{\mathrm{a}}$, Sarunya Hengpraprom ${ }^{\mathrm{a}}$, Chanvit Trarathep ${ }^{\mathrm{b}}$ \\ ${ }^{a}$ Department of Preventive and Social Medicine, Faculty of Medicine, Chulalongkorn University, \\ Bangkok 10330, \\ ${ }^{b}$ Bureau of Health Administration, Office of Permanent Secretary, Ministry of Public Health, \\ Nonthaburi, Thailand
}

\begin{abstract}
Background: Thailand has been facing a gradual increase in use of cross-border health care. Nevertheless, no evidence regarding factors influencing cross-border use of health care by Laotian patients in public Thai hospitals among this group has been established.

Objectives: To assess the use of cross-border health care by Laotian patients, and factors that may influence health services in public Thai hospitals along the border.

Methods: This study consisted of two parts. (1) Site-visits to 53 Thai public hospitals along the Thai-Laos border during May to July 2011 and collection of data regarding the use of health care services by Laotian patients. (2) A structured questionnaire survey was conducted via face interviews by trained researchers. Findings were analyzed using descriptive statistics and multiple logistic regression.

Results: The most common conditions for which treatment was sought were common diseases and basic operative procedures. All hospitals had been facing substantial financial burden, particularly for inpatient care. The analysis of use indicated that a perception of differences in the quality of health services, ability to pay for treatment anywhere, and distance to health services were three major factors affecting the decision of Laotian patients to cross the border to obtain health care in Thailand. Interviews with hospital directors and staff revealed that more financial support and a clear policy for care of Laotian patients was needed.

Conclusions: The perception of better quality of health care in Thailand by Laotian patients was the major factor affecting cross-border use of health care services. Assistance to improve healthcare in Laos and financial support for subsidizing care for the indigent Laotian patients is needed.
\end{abstract}

Keywords: Cross-border, health care services, hospital, Laos, Thailand

Cross-border health care for migrants and travelers has been problematic worldwide. Publications dealing increased travel and migration within the European Union (EU) because of health care have appeared from Europe. Increasing migration from Africa, the Middle East and parts of Asia because of health care has also been reported [1-13]. Crossborder health issues have long been of concern elsewhere in the world including within the Americas, Africa, and Southeast Asia regions [14-22]. Crossborder health care is a great challenge to public health systems of host countries because it leads to critical accessibility issues and, importantly, equity and

Correspondence to: Jiruth Sriratanaban, Department of Preventive and Social Medicine, Faculty of Medicine, Chulalongkorn University, Bangkok 10330, Thailand.

E-mail:sjiruth@gmail.com financial security of the affected health care systems. On a governmental level, cross-border health care is directly related to treaty structures with neighboring countries, and the organization and capability of their domestic social security and health care systems that comes with cross-border health care [23-25]. In light of the establishment of the ASEAN Economic Community (AEC) scheduled for 2015, Thailand has been facing a gradual increase in the use of crossborder health care. While financial problems for the providers of care have been increasing, there have been few advances in better social welfare schemes in many areas. The impact of cross-border health care on less fortunate patients and on public hospitals along the border is significant and worsening.

A small survey study of Laotians living near the Thai-Lao border in 2004-2009, showed that many Laotian patients did cross the border to use Thai health 
care services. This was because of their perception of the severity of their illnesses and their view of the greater quality of Thai health services [26, 27]. There were also some unofficial reports of Laotian patients receiving health services from Thai health centers and hospitals in provinces located more distantly to the border. In this study, we aimed to explore the crossborder use of health services by Laotian patients and the factors that might influence the situation. The findings were expected to provide policy implications for better long-term management of issues related to cross-border health care.

\section{Method}

\section{Study design and settings}

This study used a stratified cluster sampling method and consisted of 2 parts: (1) hospital site-visits to 53 sites along the Thai-Laos border and (2) multisite hospital-based patient surveys. Settings included all Thai public hospitals under the Ministry of Public Health along the 1,810-kilometer Thai-Laos border. There were 42 community hospitals in districts adjacent to the border and 11 general or tertiary-care hospitals in the border provinces.

\section{Sampling and measurement}

Part I: Thai hospital site-visits

The sample totaled 53 Thai public hospitals in 11 provinces along the Thai-Laos border. They were visited during May to July of 2011. The data collected included geographic setting, hospital size (number of beds), boundary posts, and travel mode of Laotian patients. Hospital statistics were collected and reviewed to determine the number of services, most common diseases found in cross-border patients, and financial reports of hospitals over the past three fiscal years from 2008 to 2010.

Interviews involved hospital directors and heads of wards. Finance and social work departments were contacted to gather more information regarding the workload, financial management of Laotian patients, and any suggestions for the Ministry of Public Health.

\section{Part II: Patient surveys}

Surveys were conducted of Laotian patients who used health services in the 53 Thai government hospitals along the border during May to July, 2011. At each hospital, basic demographic characteristics of 15-30 patients (varying upon hospital size) were collected. The inclusion criteria for participants were:
(1) 18 years of age and over, (2) using health services at target hospitals during the period of data collection, and (3) ability to provide written informed consent for participation in the study.

The structured questionnaire was developed using relevant literature reviews and tests of content validity. Pre-interviews were conducted to adjust interviewing content. After completion of data collection, the questionnaire was translated into Lao by a LaotianThai translator with fluent understanding of both cultures and languages. The questionnaire asked for basic demographic information and qualitative information including perception of severity of disease for which cross-border treatment was being sought, perception of treatment difficulty, benefit from services, behavior of providers, and perceived difference in health service quality between Thai and Lao facilities.

All assistant researchers were trained in observation and data collection methods by the principal investigator. Questionnaires were administered to patients at the end of service or treatment.

\section{Ethical consideration}

This study was approved by the Institutional Review Board of the Faculty of Medicine, Chulalongkorn University and the Ethical Review Committee for Research in Human Subjects, Ministry of Public Health, Thailand. The Health Insurance System Research Office (HISRO) and Health System Research Office (HSRI), Thailand, who supported the study, approved publication of our original findings.

\section{Data analysis}

All questionnaires were evaluated for accuracy before analysis. The analysis consisted of 2 parts: the first part consisted of descriptive statistics including data to determine the magnitude of problems. In the second part, data from the patient participants were categorized into two groups: those with an intention to return to Thai hospitals for follow up or new care, and those with no intention to return. The first group were new patients. Data recorded included whether it was the participant's first visit, and whether they had previous experience of using public health services in Laos during the past six months. The data from the second group were collected the same way, but from Laotian patients who had received health services in Lao hospitals along the border, and with previous experience of treatment in Thailand's public health 
services not more than 6 months before seeking treatment in Laos, and then not returning to Thailand for further treatment. Sample size was determined to be 371 persons per group [28]. Multiple logistic regression was used to analyze intention to return for future services. $P<0.05$ was considered significant.

\section{Results}

\section{Part I: Hospital site-visits}

A total of 53 hospitals were classified according to the number of beds. Small hospitals had 60 beds or less, medium hospitals had 61-200 beds, and large hospitals had over 200 beds. Only 41 hospitals (77\%) provided the required information and were used as representative of all 53 hospitals. Included in these 41 were 21 small, 8 medium, and 12 large hospitals. The remaining 12 hospitals distributing in the same geographic area did not have characteristics different from the 41 hospitals selected.

The hospitals along the border had a geographic relationship with 5 types of boundary posts: permanent crossing point, temporary crossing point (open every day), temporary crossing point (open some days), local crossing point (used by local people), and gateway or route to the border. Hospitals along a permanent boundary post had higher status and population and larger size than hospitals along temporary and tradition boundary posts, respectively. Hospitals on gateway or route to the border were the largest hospitals and had the highest status. In addition, the type of boundary post was directly related to the socioeconomic status of the community it served. Permanent boundary posts and gateways on a route to the border had higher socioeconomic status than temporary and traditional boundary posts.

Hospital data reported an increasing number of Laotian patient admissions and outpatient visits in all types of hospitals over the past three years [29] (Table 1). Reports from the hospitals showed that Laotian patients were commonly not able to pay for health services. These health care expenses were usually absorbed by the hospitals as humanitarian assistance as they could not be reimbursed from the Thailand Ministry of Public Health or Thailand National Health Security Office. This led to a financial burden on the hospitals.

Table 1. Cross-border health service utilization in hospitals over the past 3 fiscal years

\begin{tabular}{|c|c|c|c|c|c|c|c|}
\hline \multirow[t]{2}{*}{ Topic } & \multirow{2}{*}{$\begin{array}{l}\text { Size of } \\
\text { Hospital }\end{array}$} & \multicolumn{3}{|c|}{ Outpatient Services } & \multicolumn{3}{|c|}{ Inpatient Services } \\
\hline & & 2008 & 2009 & 2010 & 2008 & 2009 & 2010 \\
\hline \multirow{4}{*}{$\begin{array}{l}\text { Total Number of } \\
\text { patients } \\
(\times 1,000 \text { person })\end{array}$} & Small & 15.5 & 16.7 & 17.9 & 2.9 & 3.2 & 3.8 \\
\hline & Medium & 19.7 & 20.2 & 27.3 & 4.5 & 4.6 & 6.1 \\
\hline & Large & 12.1 & 15.0 & 16.6 & 6.4 & 6.8 & 7.9 \\
\hline & Total & 47.3 & 51.9 & 61.8 & 13.8 & 14.6 & 17.8 \\
\hline \multirow{4}{*}{$\begin{array}{l}\text { Total Number of visits } \\
(\times 1,000 \text { times })\end{array}$} & Small & 22.8 & 24.7 & 27.2 & 3.6 & 4.3 & 4.9 \\
\hline & Medium & 29.3 & 31.2 & 40.7 & 4.8 & 4.9 & 6.5 \\
\hline & Large & 20.9 & 25.3 & 28.9 & 6.9 & 7.2 & 8.5 \\
\hline & Total & 73 & 81.2 & 96.8 & 15.3 & 16.4 & 19.9 \\
\hline \multirow{4}{*}{$\begin{array}{l}\text { Fees for Service }^{\dagger} \\
\left(\times 10^{6} \text { baht }\right)\end{array}$} & Small & 6.7 & 8.0 & 25.8 & 5.6 & 7.9 & 9.1 \\
\hline & Medium & 11.6 & 11.7 & 13.1 & 8.1 & 10.4 & 13.5 \\
\hline & Large & 9.9 & 12.4 & 13.7 & 75.4 & 85.1 & 105.1 \\
\hline & Total & 28.2 & 32.1 & 52.6 & 89.1 & 103.4 & 127.7 \\
\hline \multirow{3}{*}{$\begin{array}{l}\% \text { of service payment } \\
\text { of Laotian patients }{ }^{\ddagger}\end{array}$} & Small & 40.3 & 38.9 & 14.1 & 28.4 & 29.9 & 30.1 \\
\hline & Medium & 58.9 & 58.2 & 52.8 & 65.7 & 74.5 & 63.5 \\
\hline & Large & 80.4 & 74.5 & 85.3 & 49.9 & 41.1 & 53.9 \\
\hline
\end{tabular}

†Fees for services: information is limited because of the inability of hospitals to categorize service charge and total hospital fee collected by ethnicity in their database. The Laotian patients are charged the same as local Thai patients $\ddagger \%$ of service payment by Laotian patients: calculated from the patients’ payment and charge for services 
According to International Statistical Classification of Diseases and Related Health Problems, tenth revision (ICD-10) of the World Health Organization 2007 and Classification of Procedures (ICD-9-CM) 2005, we found that over the past three years, most common diseases in cross-border patients were not classified as severe (Table 2). Most operative procedures provided in small hospitals were simple, while more complex operations requiring more expertise were provided at larger hospitals [29] (Table 2).

Interviews with hospital directors and heads of wards revealed that communication barriers, cultural diversity, and the nature of diseases and their management caused an increase in workload when dealing with a Lao patient compared with a Thai patient. The hospitals varied in how they handled the financial burden caused by cross-border patients without ability to pay. Hospitals with good financial administrative skills and a screening system controlled the workload by collaborating with social workers, nongovernmental organizations, and the local immigration bureaus. Collectively, hospital staff suggested that there was an urgent need for proper financial management of cross-border patients in a centralized manner such as a clear policy from the Ministry of Public Health or government.

\section{Part II: Patient survey}

A total of 1,220 patients were included in this study. Their mean age was $37.1 \pm 15.0$ years (range 18 to 87 years) and $62.1 \%$ were female. Most (58.8\%) lived close to the border (distance to service $\leq 50$ kilometers). There were $57.2 \%$ of patients who perceived a difference in health care services between Thailand and Laos. Analysis of factors associated with intention to return to use health service in Thailand, indicated the following factors: occupation (OR 2.78, 95\% CI 2.034-3.789), education (OR 1.59, 95\% CI 1.134-2.236), ability to pay (OR 2.52, 95\% CI 1.804-3.531), distance to service (OR 1.86, 95\% CI 1.283-2.701), travel time (OR 1.56, 95\%CI 1.1002.225), and perceived difference in quality of health services between Thai and Lao health care providers (OR 3.30, 95\% CI 2.364-4.607). All favored intention to return to Thailand for health care services (Table 3).

Table 2. ICD10 ${ }^{\dagger}$ Top 5 diseases of Lao patients treated in the hospitals over 3 years

\begin{tabular}{|c|c|c|c|}
\hline \multirow[t]{2}{*}{ Disease } & \multicolumn{3}{|c|}{ Fiscal year } \\
\hline & 2009 & 2010 & 2011 \\
\hline \multirow{4}{*}{$\begin{array}{l}\text { Outpatient } \\
\text { department(OPD) }\end{array}$} & $\begin{array}{l}\text { Dyspepsia (K30) } \\
\text { non-insulin-dependent DM } \\
\text { (E11) }\end{array}$ & $\begin{array}{l}\text { Dyspepsia (K30) } \\
\text { non-insulin-dependent DM } \\
\text { (E11) }\end{array}$ & $\begin{array}{l}\text { Dyspepsia (K30) } \\
\text { non-insulin-dependent DM (E11) }\end{array}$ \\
\hline & $\begin{array}{l}\text { Supervision of normal } \\
\text { pregnancy (Z34) }\end{array}$ & $\begin{array}{l}\text { General medical examination } \\
\text { (Z000) }\end{array}$ & $\begin{array}{l}\text { Supervision of normal pregnancy } \\
\text { (Z34) }\end{array}$ \\
\hline & $\begin{array}{l}\text { Essential (primary) hypertension } \\
\text { (I10) }\end{array}$ & $\begin{array}{l}\text { Supervision of normal } \\
\text { pregnancy (Z34) }\end{array}$ & $\begin{array}{l}\text { Essential (primary) hypertension } \\
\text { (I10) }\end{array}$ \\
\hline & $\begin{array}{l}\text { acute upper URI, unspecified } \\
\text { (J069) }\end{array}$ & $\begin{array}{l}\text { Essential (primary) } \\
\text { hypertension (I10) }\end{array}$ & $\begin{array}{l}\text { General medical examination } \\
\text { (Z000) }\end{array}$ \\
\hline \multirow{5}{*}{$\begin{array}{l}\text { Inpatient } \\
\text { department(IPD) }\end{array}$} & $\begin{array}{l}\text { Diarrhea and gastroenteritis of } \\
\text { presumed infectious origin } \\
\text { (A09) }\end{array}$ & $\begin{array}{l}\text { Diarrhea and gastroenteritis of } \\
\text { presumed infectious origin } \\
\text { (A09) }\end{array}$ & $\begin{array}{l}\text { Diarrhea and gastroenteritis of } \\
\text { presumed infectious origin (A09) }\end{array}$ \\
\hline & $\begin{array}{l}\text { Spontaneous vertex delivery } \\
\text { (O800) }\end{array}$ & $\begin{array}{l}\text { Spontaneous vertex delivery } \\
\text { (O800) }\end{array}$ & $\begin{array}{l}\text { Spontaneous vertex delivery } \\
\text { (O800) }\end{array}$ \\
\hline & Pneumonia, unspecified (J189) & Pneumonia, unspecified (J189) & $\begin{array}{l}\text { Septicemia, unspecified, septic } \\
\text { shock (A419) }\end{array}$ \\
\hline & $\begin{array}{l}\text { Singleton, born in hospital } \\
\text { (Z380) }\end{array}$ & $\begin{array}{l}\text { Singleton, born in hospital } \\
\text { (Z380) }\end{array}$ & Pneumonia, unspecified (J189) \\
\hline & $\begin{array}{l}\text { Septicemia, unspecified, septic } \\
\text { shock (A419) }\end{array}$ & $\begin{array}{l}\text { Septicemia, unspecified, septic } \\
\text { shock (A419) }\end{array}$ & $\begin{array}{l}\text { Singleton, born in hospital } \\
\text { (Z380) }\end{array}$ \\
\hline
\end{tabular}

†ICD10: International Statistical Classification of Diseases and Related Health Problems, Tenth Revision (ICD-10) of the World Health Organization, 2007 
Table 3. Laotian patient demographics and basic information between no intention to return (No ITR) and intention to return (ITR) groups

\begin{tabular}{|c|c|c|c|c|c|c|}
\hline Characteristic & $\begin{array}{l}\text { Total } \\
(\mathrm{N}-1,220)\end{array}$ & $\begin{array}{l}\text { NoITR } \\
(n=305) \\
\text { No.(\%) }\end{array}$ & $\begin{array}{l}\text { ITR } \\
(n=915) \\
\text { No.(\%) }\end{array}$ & $\boldsymbol{P}$ & $\begin{array}{l}\text { Crude } \\
\text { Odds Ratio }^{\ddagger} \\
(95 \% \text { CI })\end{array}$ & $\begin{array}{l}\text { Adjusted } \\
\text { Odds Ratio } \\
\text { (95\% CI) }\end{array}$ \\
\hline $\begin{array}{l}\text { Age (years), } \\
\text { mean } \pm S D\end{array}$ & 1,220 & $37.3 \pm 14.3$ & $37.1 \pm 15.2$ & 0.072 & $0.99(0.978-0.998)$ & $0.99(0.980-1.000)$ \\
\hline $\begin{array}{l}\text { Sex, only female } \\
\text { Marital status }\end{array}$ & 758 & 195(63.9) & $563(61.5)$ & \multirow[t]{3}{*}{$\begin{array}{l}0.453 \\
0.012 *\end{array}$} & $0.98(0.978-0.999)$ & N/A \\
\hline $\begin{array}{l}\text { Single/widowed/ } \\
\text { divorced/separated }\end{array}$ & 355 & 106(34.8) & $249(27.2)$ & & reference & N/A \\
\hline $\begin{array}{l}\text { Married } \\
\text { Ability to pay }\end{array}$ & 865 & 199(65.2) & $666(72.8)$ & & $1.24(0.887-1.727)$ & \\
\hline Unable to pay & 345 & 111(36.9) & $234(25.6)$ & \multirow[t]{2}{*}{$<0.001^{*}$} & reference & reference \\
\hline $\begin{array}{l}\text { Able to pay } \\
\text { Occupation }\end{array}$ & 869 & $190(63.1)$ & $679(74.4)$ & & $2.58(1.828-3.641)$ & $2.52(1.804-3.531)$ \\
\hline Others $^{\dagger+\dagger}$ & 599 & $207(67.9)$ & $392(42.8)$ & \multirow[t]{3}{*}{$<0.001^{*}$} & reference & reference \\
\hline Agriculture & 621 & 98(32.1) & $523(57.2)$ & & 2.64(1.197-3.638) & $2.78(2.034-3.789)$ \\
\hline Education & & & & & & \\
\hline Educated & 797 & 223(73.1) & $574(62.7)$ & \multirow[t]{2}{*}{$0.001 *$} & reference & reference \\
\hline Not educated & 423 & $82(26.9)$ & 341(37.3) & & $1.59(1.133-2.236)$ & $1.59(1.134-2.236)$ \\
\hline Travel time (hours) & & & & & & \\
\hline$>1$ & 664 & 176(60.9) & $488(56.1)$ & \multirow[t]{5}{*}{0.152} & reference & reference \\
\hline$\leq 1$ & 495 & 113(39.1) & 382(43.9) & & 1.54(1.082-2.197) & $1.56(1.100-2.225)$ \\
\hline Distance to service & e (Kilomete & & 0.317 & & & \\
\hline$\leq 50$ & 717 & $182(65.5)$ & $535(62.1)$ & & reference & reference \\
\hline$>50$ & 422 & $96(34.5)$ & $326(37.9)$ & & $1.87(1.283-2.712)$ & $1.86(1.283-2.701)$ \\
\hline \multicolumn{7}{|c|}{ Perception of severity of disease } \\
\hline Not severe & 645 & $154(50.5)$ & 491(53.7) & \multirow[t]{2}{*}{0.337} & reference & \multirow[t]{2}{*}{ N/A } \\
\hline Severe & 575 & 151(49.5) & 424(46.3) & & $1.02(0.740-1.415)$ & \\
\hline \multicolumn{7}{|c|}{ Perception of treatment difficulty } \\
\hline Not complicated & 346 & $90(29.5)$ & $256(28.0)$ & \multirow[t]{2}{*}{0.608} & reference & \multirow[t]{2}{*}{ N/A } \\
\hline Complicated & 874 & 215(70.5) & $659(72.0)$ & & $1.07(0.758-1.521)$ & \\
\hline \multicolumn{7}{|c|}{ Perceived difference Score in health services quality between Thailand-Laos } \\
\hline$\leq 10$ & 698 & 229(75.1) & $469(51.3)$ & \multirow[t]{2}{*}{$0.001 *$} & reference & reference \\
\hline$>10$ & 522 & 76(24.9) & 446(48.7) & & $3.31(2.366,4.626)$ & $3.30(2.364,4.607)$ \\
\hline
\end{tabular}

†† ¥: logistic regression, $¥$ : multiple logistic regression (stepwise method)

\section{Discussion}

Thailand is a major target for cross-border health services. There has been a gradual increase in demand for cross-border health services by Laotian patients along the Thai-Lao border. These include primary health care and more complex medical services. The present study indicated increasing numbers of Laotian patients are traveling to the outpatient and inpatient services at all boundary facilities. The most common care requested was for primary care services. Nevertheless, primary health care services have affected negatively the already strained financial status of hospitals along the border. Laotian patients along the border have no insurance coverage for health care and have to pay for all medical expenses [29-30]. Moreover, the socioeconomic status along the border relates to type of boundary post. Most temporary boundary posts are in a low socioeconomic areas and $67.9 \%$ of hospitals along the border are near temporary or traditional open boundary posts. This leads an inability to pay for services and has significantly affected the financial status of Thai government hospitals along the border. 
In this survey, conditions which have led to the use of cross-border health services in Thailand were mostly common problems such as gastrointestinal diseases, upper respiratory diseases, pregnancy and delivery. This indicates the inadequacy of primary health care in more remote areas in Laos. This is in addition to a perceived difference in the quality of health care services between Laos and Thailand. Inability of Laotian patients to pay is a key problem for the Thai government hospitals along the border that are not adequately supported for such services by the Thai government. A similar cross-border health care service crisis exists in some European Union countries facing an increasing burden of indigent migrants. Although there are many similarities, a significant difference is that the Thailand-Laos area has more limited resources [2].

Our recommendation for Thai policy makers as the host country includes considerable assistance to improve health services in the neighboring country (Laos) to help close the quality gap, particularly to strengthen primary health care in remote areas to build the confidence of patients in such local facilities. In addition, a short-term solution includes the need to provide financial support for the hospitals along the border to allow for poor Laotian patients that need urgent medical services. Future studies should seriously consider creating an ASEAN international health fund, or universal coverage with transportability. This would require discussions and proactive planning by officials from both sides of the border.

A strength of this study was that the multiple site questionnaires were administered at each and every site visit. This led to a comprehensive discovery of actual situations and contexts that occurred at each site. The larger number of study participants acquired at the larger better equipped hospitals might have influenced Laotian patients' perception of health care service across the border. Moreover, causal factors might also be uncovered via this type of crosssectional survey. A limitation of this study was that it was designed for descriptive rather than analytical evaluation.

In conclusion, the higher quality of medical services on the Thai side of the border was the main factor causing high use of cross-border health care services by Laotian patients. In view of the upcoming ASEAN Economic Community (AEC) in 2015, which may intensify the situation, the development of international cooperation in public health between the
2 countries is urgently needed. More funding for hospitals at the border and proper administrative and financial management policy from the health care authorities of both countries should be considered.

\section{Acknowledgement}

We express our sincere gratitude to the study participants and assistant researchers at the sites. This study was supported by The $90^{\text {th }}$ Anniversary of Chulalongkorn University Fund (Ratchadaphiseksomphot Endowment Fund) and Health Insurance System Research Office for Health System Research Institute.

The authors declare that they have no conflict of interest.

\section{References}

1. Österle A. Health care across borders: Austria and its new EU neighbours. J Eur Soc Pol. 2007; 17:112-24.

2. Legido-Quigley H, Glinos I, Baeten R, McKee M. Patient mobility in the European Union. BMJ. 2007; 334:188-90.

3. Evers S, Paulus A, Boonen A. Integrated care across borders: possibilities and complexities. Int J Integr Care. 2001;1:e18.

4. Groene O, Poletti P, Vallejo P, Cucic C, Klazinga N, Sunol R. Quality requirements for cross-border care in Europe: a qualitative study of patients', professionals' and health care financiers' views. Qual Saf Health Care. 2009; 18 Suppl 1:i15-21.

5. Sunol R, Garel P, Jacquerye A. Cross-border care and health care quality improvement in Europe: the MARQuIS research project. Qual Saf Health Care. 2009; 18 Suppl 1:i3-7.

6. den Exter A. Patient mobility in European Union: health spas in Ischia, Italy. Croat Med J. 2005; 46: 197-200.

7. Brand H, Hollederer A, Wolf U, Brand A. Crossborder health activities in the Euregios: good practice for better health. Health Policy. 2008; 86:245-54.

8. Hermans HE, den Exter A. Cross-border alliances in health care: international co-operation between health insurers and providers in the Euregio Meuse-Rhine. Croat Med J. 1999; 40:266-72.

9. Vallejo P, Sunol R, Van Beek B, Lombarts MJ, Bruneau C, Vlcek F. Volume and diagnosis: an approach to cross-border care in eight European countries. Qual Saf Health Care. 2009; 18 Suppl 1:i8-14.

10. Vallejo P, Sunol R. MARQulS: quality improvement strategies for European cross-border health care. 
Qual Saf Health Care. 2009; 18 Suppl 1:i1-2.

11. Sellars C. Cross border access to health care services within the European Union. World Hosp Health Serv. 2006; 42:23-5.

12. Crivelli L, Zweifel P. Modeling cross-border care in the EU using a principal-agent framework. Dev Health Econ Public Policy. 1998; 6:229-57.

13. Rich RF, Merrick KR. Cross border health care in the European union: challenges and opportunities. J Contemp Health Law Policy. 2006; 23:64-105.

14. Lester H, Hobbs FD. Major policy changes for primary care: potential lessons for the US New Model of family medicine from the quality and outcomes framework in the United Kingdom. Fam Med. 2007; 39: 96-102.

15. Katz SJ, Verrilli D, Barer ML. Canadians' use of U.S. medical services. Health Aff (Millwood). 1998; 17: 225-35.

16. Davies BJ. Canada's health system. Croat Med J. 1999; 40:280-6.

17. Cohen L. Quebec, Ontario battle over cross-border health care charges. CMAJ. 1993; 148:1206-9.

18. Chavez LR, Cornelius WA, Jones OW. Mexican immigrants and the utilization of U.S. health services: the case of San Diego. Soc Sci Med. 1985; 21:93-102.

19. Rivera JO, Ortiz M, Cardenas V. Cross-border purchase of medications and health care in a sample of residents of El Paso, Texas, and Ciudad Juarez, Mexico. J Natl Med Assoc. 2009; 101:167-73.

20. Byrd TL, Law JG. Cross-border utilization of health care services by United States residents living near the Mexican border. Rev Panam Salud Publica. 2009; 26:95-100.

21. Agyepong IA, Adjei S. Public social policy development and implementation: a case study of the Ghana National Health Insurance scheme. Health Policy Plan. 2008; 23:150-60.

22. Thomas S, Gilson L. Actor management in the development of health financing reform : health insurance in South Africa, 1994-1999. Health Policy
Plan. 2004; 19:279-91.

23. Nemie P, Kassim J. Cross-border issues in the development of medical tourism in Malaysia: legal challenges and opportunities. J Law Med. 2009; 17: 59-73.

24. Lopes Cardozo B, Talley L, Burton A, Crawford C. Karenni refugees living in Thai-Burmese border camps: traumatic experiences, mental health outcomes, and social functioning. Soc Sci Med. 2004; 58:2637-44.

25. Kanchanachitra C, Lindelow M, Johnston T, Hanvoravongchai P, Lorenzo FM, Huong NL, et al. Human resources for health in southeast Asia: shortages, distributional challenges, and international trade in health services. Lancet. 2011; 377:769-81.

26. Bochaton $\mathrm{A}$. The rise of a transnational healthcare paradigm. Thai hospitals at the crossroads of new patient flows, Eur J Transnational Studies (EJOTS). 2013; 5:54-80.

27. Bochaton A. Cross-border mobility and social networks: Laotians seeking medical treatment along the Thai border. Soc Sci Med 2014; (in press) doi: 10.1016/j.socscimed. 2014.10.022.

28. Lemeshow S, Hosmer Jr DW, Klar J, Lwanga SK. Adequacy of Sample Size in Health Studies, New York: John Wiley \& Sons Ltd; 1990.

29. Health Insurance System Research Office. Health Care Service Used by Lao Patients in Thailand; The impact on Thai public hospitals. [online]. 2013 [cited 2014 Jan 14]; [in Thai] Available from: http://www.hisro. or.th/main/modules/research/attachservices/174/ Full-text.pdf

30. Tangcharoensathien V, Wibulpholprasert S, Nitayaramphong S. Knowledge-based changes to health systems: the Thai experience in policy development. Bull World Health Organ. 2004; 82:750-6.

31. Tangcharoensathien V, Patcharanarumol W, Ir P, Aljunid SM, Mukti AG, Akkhavong K, et al. Healthûnancing reforms in southeast Asia: challenges in achieving universal coverage. Lancet. 2011; 377 : 863-73. 